\title{
Upper gastrointestinal bleeding as a metastatic manifestation of breast cancer: A case report and review of the literature
}

\author{
Tony Reiman MD, Charles A Butts MD FRCPC
}

T Reiman, CA Butts. Upper gastrointestinal bleeding as a metastatic manifestation of breast cancer: A case report and review of the literature. Can J Gastroenterol 2001;15(1):67-71.

CASE PRESENTATION: A 64-year-old woman with known metastatic lobular breast cancer presented with fever, epigastric pain, hematemesis and melena. A bleeding, ulcerated gastric metastasis was found and was treated with endoscopic therapy, omeprazole and hormonal therapy. The patient was alive and well 13 months later. The bleeding was probably precipitated by necrosis of the lesion during chemotherapy.

DISCUSSION: Gastrointestinal tract metastases from primary breast carcinoma are present in $14 \%$ to $35 \%$ of cases in autopsy series, with gastric involvement in $6 \%$ to $18 \%$ of cases. Recognized much less commonly during life than in autopsy studies, they can occur anywhere in the gut and can mimic virtually any gastrointestinal disorder. Endoscopy and barium studies facilitate diagnosis. Gastric lesions that have been noted include 'linitis plastica', nodules, polyps and ulcers. They are usually due to lobular breast carcinoma and resemble primary gastric carcinoma on microscopy. Reported cases of bleeding gastric metastases have been treated successfully with various local and systemic modalities. The median survival time of reviewed cases was four months from presentation (with a range of zero to 24 months).

CONCLUSIONS: Gastrointestinal metastasis is an underdiagnosed complication of breast cancer. Gastrointestinal bleeding from metastatic breast cancer is an uncommon presentation that is readily diagnosed and that can be treated successfully by endoscopic hemostatic therapy.

Key Words: Breast cancer; Gastrointestinal bleeding

\section{Hémorragie digestive haute comme} manifestation métastatique d'un cancer du sein : Rapport de cas et revue de la littérature

PRÉSENTATION DU CAS : Une femme de 64 ans atteinte d'un cancer du sein lobulaire métastatique connu s'est présentée pour fièvre, douleur épigastrique, hématémèse et méléna. On a découvert des métastases gastriques ulcérées et hémorragiques que l'on a traitées par technique endoscopique, oméprazole et hormonothérapie. La patiente est vivante et se porte bien 13 mois plus tard. L'hémorragie a probablement été déclenchée par la nécrose de la lésion durant la chimiothérapie.

DISCUSSION : Les métastases des voies digestives provenant d'un cancer du sein primaire s'observent dans 14 à $35 \%$ des cas lors des autopsies, avec une atteinte gastrique dans 6 à $18 \%$ des cas. Reconnues beaucoup moins souvent chez l'individu vivant qu'à l'autopsie, elles peuvent s'observer n'importe où dans l'appareil digestif et imiter une foule d'autres problèmes digestifs. L'endoscopie et les examens au baryum facilitent le diagnostic. Les lésions gastriques qui ont été notées sont la linite plastique, les nodules, les polypes et les ulcères. On les attribue généralement au carcinome du sein lobulaire et elles ressemblent au cancer de l'estomac primaire à la microscopie. Les cas de métastases gastriques hémorragiques rapportés ont été traités avec succès au moyen de modalités locales et systémiques diverses. Le temps de survie médian des cas passés en revue a été de quatre mois à compter de la consultation initiale (avec un éventail de 0 à 24 mois).

CONCLUSION : Les métastases gastro-intestinales représentent une complication du cancers du sein qui passe trop souvent inaperçue. Les hémorragies digestives provenant de cancers du sein métastatiques sont peu communes, mais faciles à diagnostiquer et peuvent être traitées avec succès au moyen de techniques hémostatiques endoscopiques.

Department of Medicine, Cross Cancer Institute, Edmonton, Alberta

Correspondence: Dr Charles Butts, Department of Medicine, Cross Cancer Institute, 11560 University Avenue, Edmonton, Alberta T6G 122.

Telephone 780-432-8762, fax 780-432-8888, e-mail charlesb@cancerboard.ab.ca

Received for publication September 21, 1999. Accepted October 13, 1999 
U pper gastrointestinal bleeding is an uncommon manifestation of breast cancer. A case due to the presence of an ulcerated metastatic gastric nodule is presented. The literature on gastric metastases in breast cancer patients is also reviewed.

\section{CASE PRESENTATION}

A 64-year-old woman was diagnosed in 1985 with a $3 \mathrm{~cm}$ infiltrating lobular carcinoma of the right breast (Figure 1). Estrogen and progesterone receptors were present. The patient underwent a modified radical mastectomy and axillary node dissection. Four of 11 axillary nodes were positive for metastatic disease. She was treated for one year with adjuvant chemotherapy.

Between 1990 and 1995, the patient developed metastatic disease in the lymph nodes, bones and skin. She was treated with tamoxifen and palliative radiotherapy. In 1997, multiple symptomatic liver metastases were found on a computed tomography scan of the abdomen. She had a minor response to anthracycline-based chemotherapy. Second-line hormonal therapy was then instituted but was discontinued within two months because of disease progression in the liver. An indwelling central venous catheter was inserted, and docetaxel chemotherapy was started in December 1997. Oral warfarin ( $1 \mathrm{mg}$ daily) was prescribed to prevent catheterassociated thrombosis.

In January 1998, the patient developed a fever with no identifiable cause. It was thought to be due to the malignancy. She was given naproxen for symptomatic relief but stopped taking it after three days because the fever had resolved.

The patient presented in February 1998 with a seven-day history of nausea, anorexia, mild epigastric pain and malaise. Five days before presentation she had an episode of hematemesis followed by daily melena stools. She had another milder episode of hematemesis on the day of presentation and reported lightheadedness when standing.

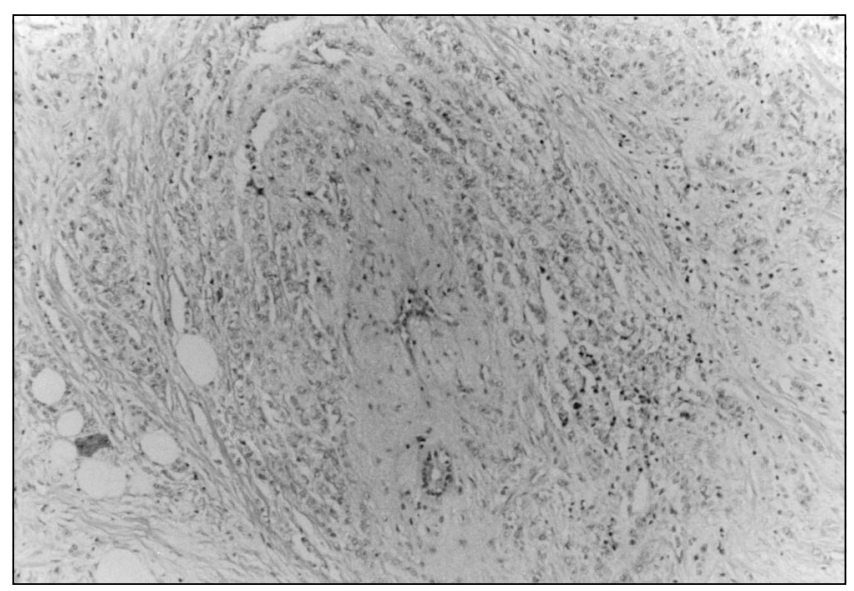

Figure 1) Hematoxylin and eosin staining of the primary breast tumour, revealing single-file strands of malignant cells within normal breast stroma, which is diagnostic of an infiltrating lobular carcinoma
Physical examination revealed conjunctival pallor. The patient's heart rate was normal; her blood pressure was 130/80 mmHg supine and 120/80 $\mathrm{mmHg}$ standing. There was mild epigastric tenderness, but no distention or peritoneal irritation was detected. The hemoglobin level was $78 \mathrm{~g} / \mathrm{L}$; three weeks previously, it had been stable at $106 \mathrm{~g} / \mathrm{L}$. The platelet count, prothrombin time and partial thromboplastin time were all normal.

The patient was admitted to hospital, and intravenous normal saline was given. Warfarin was discontinued. Two units of packed red blood cells were transfused. Gastroscopy was performed, revealing an ulcer on the anterior wall of the stomach measuring $1.5 \mathrm{~cm}$. A blood vessel was visible in the centre of the ulcer. Pooled blood had clotted in the stomach. Five millilitres of 1:10,000 adrenaline were injected into the ulcer, and the visible vessel was electrically cauterized. Oral omeprazole (20 mg twice daily) was started.

The patient's melena subsided, and her hemoglobin level stabilized at $93 \mathrm{~g} / \mathrm{L}$. Repeat endoscopy four days later showed a healing ulcer with a clean base and no blood in the stomach. The esophagus, the rest of the stomach and the duodenum were all normal in appearance. Four quadrant biopsies of the ulcer edges were obtained. Cultures and microscopic examination of the gastric mucosa for Helicobacter pylori were negative.

The pathology slides of the gastric lesion showed infiltrating malignant cells forming single-file strands within the gastric lamina propria, with some associated inflammation and necrosis. Immunoperoxidase staining for estrogen receptors was strongly positive (Figure 2). The microscopic appearance and the estrogen receptor staining were most consistent with metastatic lobular breast cancer. Biopsies of a separate area of the stomach wall showed active gastritis but no evidence of malignancy.

After seven days in hospital, the patient was discharged with a diagnosis of lobular breast carcinoma metastatic to the stomach. Chemotherapy was withheld, and third-line

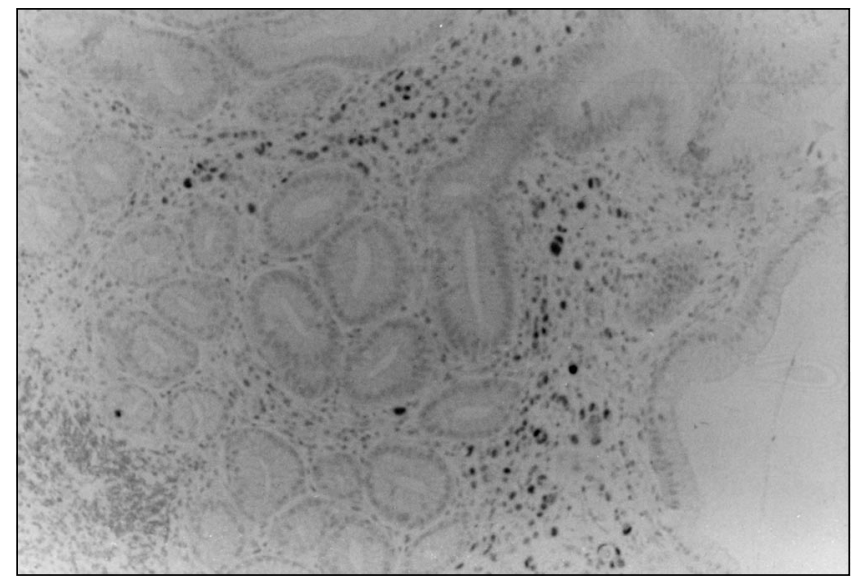

Figure 2) Immunoperoxidase staining of the gastric biopsy specimen for estrogen receptors, showing a strongly positive reaction from the malignant cells but not from the surrounding gastric tissue. The single-file organization of the malignant cells resembles the pattern seen in the primary breast tumour 
hormonal therapy was instituted. It was thought that the chemotherapy contributed to necrosis of the stomach lesion, leading to bleeding.

Follow-up endoscopy two months later showed only some residual scarring in the area of the previous ulcer. Biopsies of the area were negative for malignancy. Omeprazole was discontinued.

She subsequently required further chemotherapy and remained stable on fourth-line hormonal therapy. No further evidence of gastrointestinal bleeding had developed 13 months after the original bleed.

\section{DISCUSSION}

Gastrointestinal bleeding is an uncommonly reported manifestation of breast cancer. There are several such reports in the literature (1-11), but large series of breast cancer patients contain only rare cases (12-18). Causes of gastrointestinal bleeding in patients with breast cancer include esophageal varices due to liver metastases (8-11); bleeding esophageal (9), gastric $(2,6,7)$ or colonic metastases $(4)$; and acquired circulating anticoagulants (10). These diagnoses require consideration, along with the benign causes of gastrointestinal bleeding, such as peptic ulcer disease, gastritis and Mallory-Weiss tears.

Breast cancer has been found in virtually every location along the gastrointestinal tract, from mouth to anus $(4,19)$. Any gastrointestinal symptom or sign seems to be reproducible by breast cancer. Esophageal stricture, achalasia, bowel obstruction or perforation, biliary tract or gallbladder disease, ileitis, pancolitis, appendicitis and peritoneal carcinomatosis have all been described (4,20-22).

Breast cancer is one of the major causes of gastric metastases. In an autopsy series of patients with gastric metastases, the majority of cases (excluding lymphomas) arose in patients with melanoma, breast carcinoma or lung carcinoma $(13,23-25)$. Autopsy series in patients with breast cancer show a prevalence of metastases to the gastrointestinal tract of $14 \%$ to $35 \%$, excluding serosal and liver disease $(12,16,26,27)$. Series that reviewed gastric metastases, in particular, found a prevalence of $6 \%$ to $18 \%(5,15,16,27,28)$. These patients usually had widely disseminated breast cancer.

Gastric metastases are detected during life much less commonly than in autopsy studies, although they are occasionally the first sign of dissemination of breast cancer $(3,29)$. Case series of symptomatic gastric metastases suggest that one to two cases per year are seen in breast cancer referral centres $(1,14,17,30)$.

There are no specific symptoms of gastric metastases. The most frequent symptoms are nausea, vomiting and epigastric pain. Anorexia, weight loss, dysphagia, melena and hematemesis have all been reported. Iron deficiency anemia and guaiac-positive stools may also be presenting features $(17,19)$. Given the low prevalence of gastrointestinal metastases, most patients with breast cancer who present with these findings would be expected to have benign disease as the cause. This hypothesis is supported by a published series of 118 patients with breast cancer who were referred for endoscopy (31).
Seven cases of metastatic esophageal stenosis were found among the $39 \%$ of cases in which pathological findings had been detected. The majority of positive endoscopies revealed either benign ulceration or esophagitis.

Visualization of the stomach in patients with gastric metastases from breast cancer may reveal any of several morphologies. The most common is a 'linitis plastica' appearance due to diffuse intramural infiltration of the stomach with the tumour $(1,2,19,28,30)$. This is characterized by a narrowing of the stomach lumen, rigidity and diminished peristalsis (19). This narrowing is seen much more readily with barium studies than with endoscopy (32). Other appearances of gastric metastases include nodular or polypoid lesions and ulcerated lesions $(17,19,30)$. Among the cases reviewed that reported morphological findings, there was one published series of 31 cases of linitis plastica (1). Features of linitis plastica were reported in an additional 28 of 47 cases (60\%) with published morphological findings. Prior reviews have found that $43 \%$ to $73 \%$ of patients with gastric metastases from breast cancer present with linitis plastica $(19,30)$.

Although ductal carcinoma is by far the most common primary breast tumour (33), lobular carcinoma is the predominant histology in gastric metastases $(3,17,30)$. Among the cases reviewed, 55 of 64 cases (86\%) in which histology was reported showed lobular carcinoma. Several large clinical and autopsy series (34-40) have examined the differences in the pattern of metastases of ductal and lobular breast cancer. A significantly higher prevalence of gastrointestinal and peritoneal metastases with lobular breast cancer has been found repeatedly (34-39). Even in cases in which the primary tumour is of mixed histology, it is the lobular component that tends to appear in the stomach $(1,29)$. It has been suggested that ductal carcinomas tend to produce nodular stomach lesions, while lobular carcinomas tend to cause more diffuse disease (1), but the present case shows that this suggestion is not always true.

The pathology of gastric metastases from breast cancer suggests a hematogenous route of spreading $(2,3,19,41)$. The lesions originate in the gastric submucosa with subsequent extension into the mucosa or serosa. Signet ring cells are frequently seen $(23,42)$. Lobular breast cancer cells tend to form strands rather than glandular structures and can be difficult to distinguish from primary gastric carcinomas. Helpful distinguishing features for metastatic disease include the absence of a smooth transition to normal mucosa, a similarity to the histology of the primary tumour, and the presence of estrogen and/or progesterone receptors $(2,3,42)$. However, none of these features are pathognomonic for breast cancer metastases nor do they rule out primary gastric carcinoma.

The management of gastric metastases has varied. Successes have been documented with several approaches, including surgery, endoscopy, radiotherapy, chemotherapy and hormonal therapy $(3,16,17,29)$. Local therapy, such as surgery, to control bleeding has allowed longevity, even in patients with widespread disease (16). Most reports on the surgical management of gastric metastases predate the era of 
therapeutic endoscopy or effective systemic therapies for metastatic breast cancer $(6,16,41)$. More recent reports usually feature systemic therapy, radiotherapy and/or endoscopy as the treatments of choice $(7,17,19)$.

Survival among reported cases has varied widely. Gastrointestinal bleeding has led to early death in some of the reported cases, but survival has extended up to 24 months beyond the diagnosis of bleeding in other cases (1-11). Among 13 cases of bleeding gastric metastases where such data were published, the median length of survival from the date of the bleeding was four months. Among 15 published cases of nonbleeding gastric metastases with survival data, as well as among the 28 pooled bleeding and nonbleeding cases, the median length of survival from diagnosis was seven months (the range was zero months to longer than 3.5 years).

In the present case, it appears that a temporal association existed between the administration of chemotherapy, and the subsequent ulceration and brisk bleeding of the gastric lesion. The concomitant use of naproxen and warfarin initially (and incorrectly) suggested a benign cause of the bleeding. The combination of local endoscopic therapy and a change in the systemic therapy was successful in preventing rebleeding. It is likely that the regression of the lesion was in response to antineoplastic therapy, although the partial removal of the blood supply by electrocautery may have played a role. It is possible that the subsequent healing of the gastric mucosa was facilitated by the proton pump inhibitor.

A prolonged period of survival with good quality of life was achieved by the patient without long term omeprazole therapy. The likelihood of gastric recurrence is unknown but is probably high. Further studies on the role of gastric acidity in the pathogenesis of ulcerated gastric metastases would be

\section{REFERENCES}

1. Cormier WJ, Gaffey TA, Welch JM, et al. Linitis plastica caused by metastatic lobular carcinoma of the breast. Mayo Clin Proc 1980;55:747-53.

2. Joffe N. Metastatic involvement of the stomach secondary to breast carcinoma. AJR Am J Roentgenol 1975;123:512-21.

3. Schwarz RE, Klimstra DS, Turnbull ADM. Metastatic breast cancer masquerading as gastrointestinal primary. Am J Gastroenterol 1998;93:111-4.

4. Chang SF, Burrell MI, Brand MH, Garsten JJ. The protean manifestations of metastatic breast carcinoma. Radiology 1978;126:611-7.

5. Davis HL, Murray RK, Korbitz BC. Breast carcinoma metastatic to the stomach: report of a case in a male and review of an autopsy series. Am J Dig Dis 1968;13:868-73.

6. Conklin EF. Metastatic carcinoma of the breast presenting signs and symptoms of upper gastrointestinal hemorrhage. N Y State J Med 1963;15:2405-7.

7. Dupas JL, Delmarre J, Marti R, et al. Gastric metastasis from breast carcinoma: emergency snare-ectomy for control of hemorrhage. Endoscopy 1976;8:35-7.

8. Kurtz RC, Sherlock P, Winawer SJ. Esophageal varices: development secondary to primary and metastatic liver tumours. Arch Intern Med 1974;134:50-1.

9. Hastier P, Francois E, Delmont JP, et al. Esophageal metastases from breast cancer detected by hematemesis. Am J Gastroenterol 1994;89:289-90. (Lett)

10. Hill GR, Hickton CM, Brennan SO, et al. Acquired heparin-like anticoagulants: a second case in metastatic breast carcinoma and literature review. Clin Lab Haematol 1996;18:291-5. helpful in clarifying the potential benefit of maintenance proton pump inhibitor therapy.

\section{CONCLUSIONS}

Gastrointestinal metastases are a common but underrecognized complication of breast cancer. Gastrointestinal metastases are usually due to lobular rather than ductal carcinoma and often occur in the setting of widely disseminated disease. The clinical presentation is nonspecific and likely is often misdiagnosed as cancer cachexia, therapeutic toxicity or metabolic derangement. Visualization of the gastrointestinal tract with endoscopy and/or barium studies is helpful, and biopsies can establish the diagnosis.

Gastrointestinal bleeding in the breast cancer patient must prompt the clinician to consider metastatic disease as the cause. Bleeding gastroduodenal ulcers in the breast cancer patient may be due to metastatic, rather than peptic, disease. Treatment can be multimodal and must be individualized. Many patients with metastatic breast cancer, such as the one presented in this report, can have long term survival with good quality of life. For such patients, the aggressive management of complications such as gastrointestinal bleeding is clearly indicated.

ACKNOWLEDGEMENTS: This patient was treated at the Queen Elizabeth II Health Sciences Centre in Halifax, Nova Scotia. The authors are indebted to the gastroenterology consult team at the Queen Elizabeth II Health Sciences Centre, headed by Dr J Love, who performed the endoscopic procedures necessary for the diagnosis and treatment of this patient. Dr D Murphy, pathologist at the Queen Elizabeth II Health Sciences Centre, interpreted the pathological specimens and provided the photomicrographs.
11. Case records of the Massachusetts General Hospital. Case 38-1966. N Engl J Med 1966;275:491-6.

12. Hagemeister FB, Buzdar AU, Luna MA, Blumenschein GR. Causes of death in breast cancer: a clinicopathologic study. Cancer 1980:46;162-7.

13. Menuck LS, Amberg JR. Metastatic disease involving the stomach. Am J Dig Dis 1975;20:903-13.

14. Graham WP, Goldman L. Gastro-intestinal metastases from carcinoma of the breast. Ann Surg 1964;159:477-80.

15. Choi SH, Sheehan FR, Pickren JW. Metastatic involvement of the stomach by breast cancer. Cancer 1964;17:791-7.

16. Asch MJ, Wiedel PD, Habif DV. Gastrointestial metastases from carcinoma of the breast: autopsy study and 18 cases requiring operative intervention. Arch Surg 1968;96:840-3.

17. Taal BG, den Hartog Jager FCA, Steinmetz R, Peterse H. The spectrum of gastrointestinal metastases from breast carcinoma: I. Stomach. Gastrointest Endosc 1992;38:130-5.

18. Hartmann WH, Sherlock P. Gastroduodenal metastases from carcinoma of the breast: an adrenal steroid-induced phenomenon. Cancer 1961;14:426-31.

19. Marshall ME. Gastrointestinal metastases from carcinoma of the breast. J Ky Med Assoc 1983;81:154-7.

20. Titus AS, Baron TH, Listinsky CM, Vickers SM. Solitary breast metastasis to the ampulla and distal common bile duct. Am Surg 1997;63:512-5.

21. Cornu Labat G, Ghani A, Smith DJ, McDonald AD, Kasirajan K. Small bowel perforation secondary to metastatic carcinoma of the breast. Am Surg 1998;64:312.

22. Appel MF. Gastric metastases from breast carcinoma. Am Surg 1974;40:253-5. 
23. Washington K, Mcdonagh D. Secondary tumors of the gastrointestinal tract: surgical pathologic findings and comparison with autopsy survey. Mod Pathol 1995;8:427-33.

24. Libshitz HI, Lindell MM, Dodd GD. Metastases to the hollow viscera. Radiol Clin North Am 1982;20:487-99.

25. Telerman A, Gerard B, Van den Heule B, Bleiberg H. Gastrointestinal metastases from extra-abdominal tumors. Endoscopy 1985;17:99-101.

26. Abrams HL, Spiro R, Goldstein N. Metastases in carcinoma: analysis of 1000 autopsied cases. Cancer 1950;3:74-85.

27. Cifuentes N, Pickren JW. Metastases from carcinoma of mammary gland: an autopsy study. J Surg Oncol 1979;11:193-205.

28. Sherlock P, Hartmann WH. Adrenal steroids and the pattern of metastases of breast cancer. JAMA 1962;181:313-7.

29. Clavien PA, Laffer U, Torhost J, Harder F. Gastro-intestinal metastases as first clinical manifestation of the dissemination of a breast cancer. Eur J Surg Oncol 1990;16:121-6.

30. Madeya S, Borsch G. Gastrointestinal metastases of breast carcinoma. Gastrointest Endosc 1993;39:103-4. (Lett)

31. Madeya S, Borsch G. Upper intestinal endoscopy in 188 bronchial cancer patients and 118 breast cancer patients with abdominal symptoms. The GI Metastases Study Group. Med Klin 1992;87:631-6.

32. Hsu CC, Chen JJ, Changchien CS. Endoscopic features of metastatic tumors in the upper gastrointestinal tract. Endoscopy 1996;28:249-53.

33. Fisher B, Osborne CK, Margolese RG, Bloomer WD. Neoplasms of the breast. In: Holland JF, Blast RC Jr, Morton DL, Frei E III, Kufe DW, eds. Cancer Medicine, 4th edn. New York: Williams and Wilkins, 1997.
34. Lamovec J, Bracko M. Metastatic pattern of infiltrating lobular carcinoma of the breast: an autopsy study. J Surg Oncol 1991;48:28-33.

35. Harris M, Howell A, Chrissohou M, et al. A comparison of the metastatic pattern of infiltrating lobular carcinoma and infiltrating duct carcinoma of the breast. Br J Cancer 1984;50:23-30.

36. Borst MJ, Ingold JA. Metastatic patterns of invasive lobular versus invasive ductal carcinoma of the breast. Surgery 1993;114:637-42.

37. Jain S, Fisher C, Smith P, et al. Patterns of metastatic breast cancer in relation to histological type. Eur J Cancer 1993;29A:2155-7.

38. Dixon AR, Ellis IO, Elston CW, Blamey RW. A comparison of the clinical metastatic patterns of invasive lobular and ductal carcinomas of the breast. Br J Cancer 1991;63:634-5.

39. Sastre-Garau X, Jouve M, Asselain B, et al. Infiltrating lobular carcinoma of the breast: clinicopathologic analysis of 975 cases with reference to data on conservative therapy and metastatic patterns. Cancer 1996;77:113-20.

40. du Toit RS, Locker AP, Ellis IO, et al. An evaluation of differences in prognosis, recurrence patterns and receptor status between invasive lobular and other invasive carcinomas of the breast. Eur J Surg Oncol 1991;17:251-7.

41. Klein MS, Sherlock P. Gastric and colonic metastases from breast cancer. Am J Dig Dis 1972;17:881-6.

42. Merino MJ, Livolsi VA. Signet ring carcinoma of the female breast: a clinicopoathologic analysis of 24 cases. Cancer 1981;48:1830-7. 


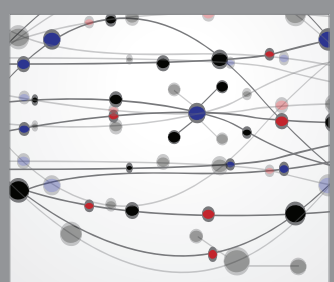

The Scientific World Journal
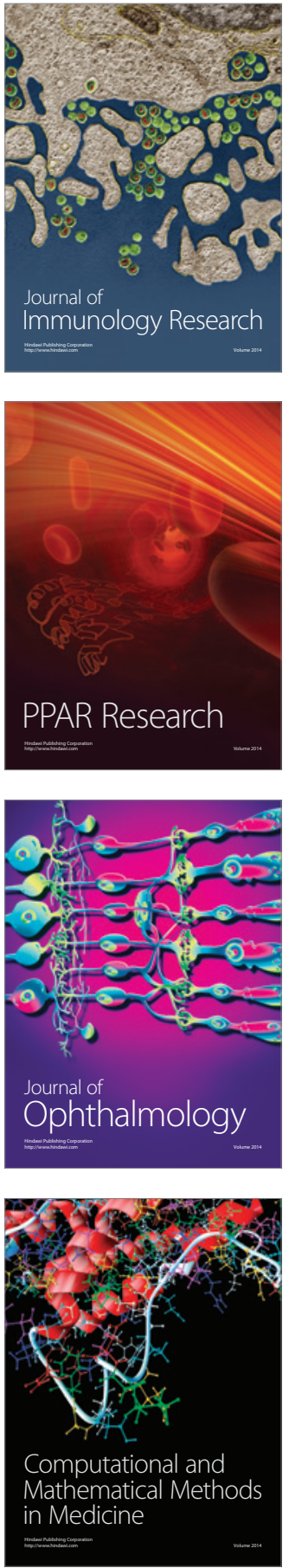

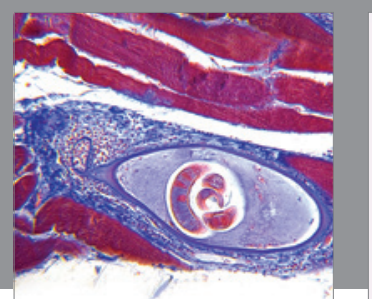

Gastroenterology Research and Practice

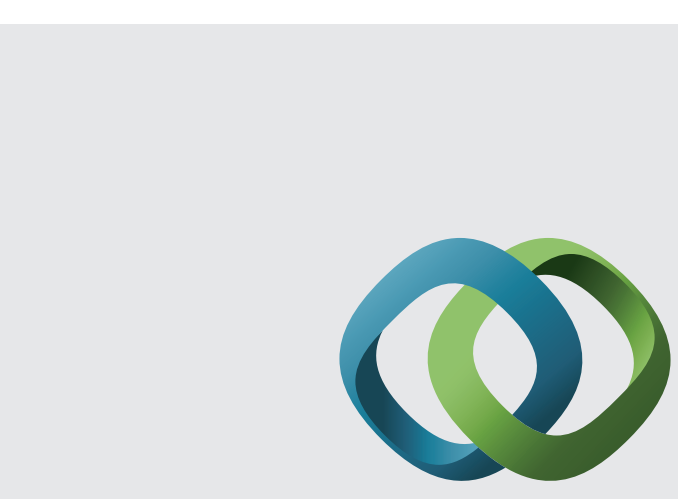

\section{Hindawi}

Submit your manuscripts at

http://www.hindawi.com
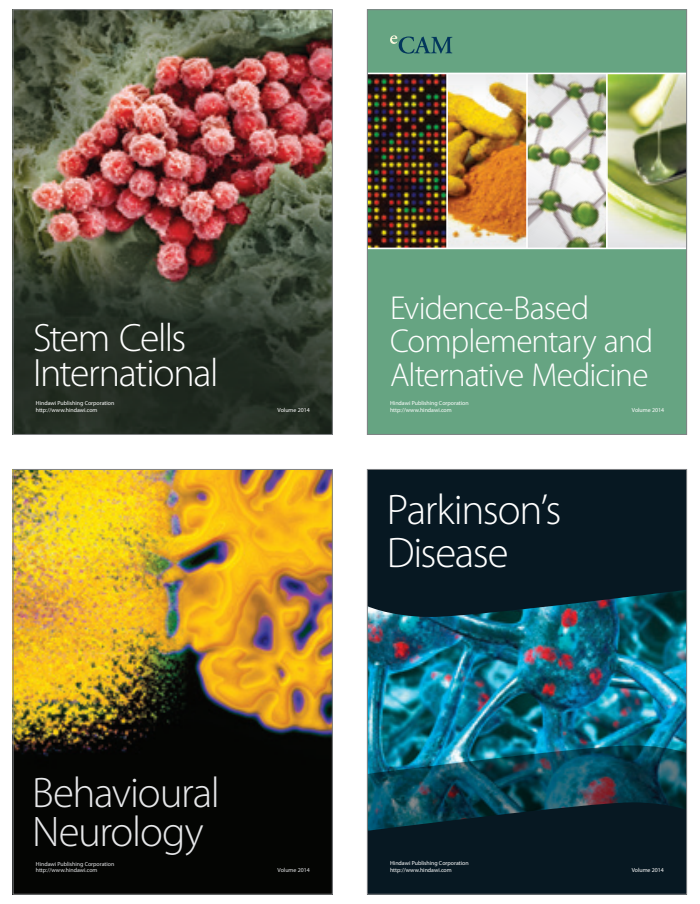
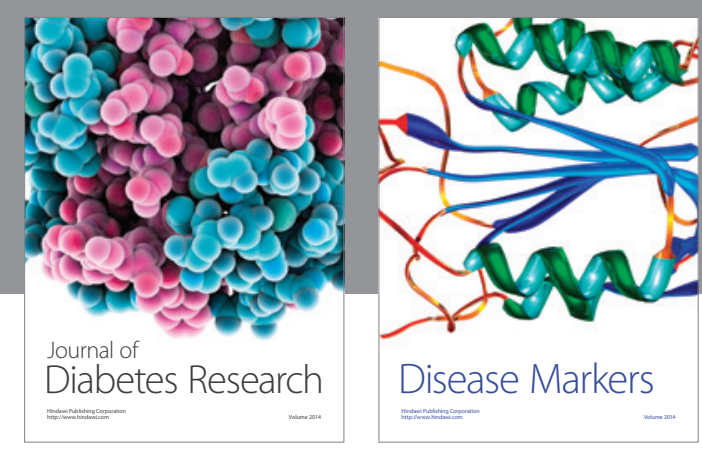

Disease Markers
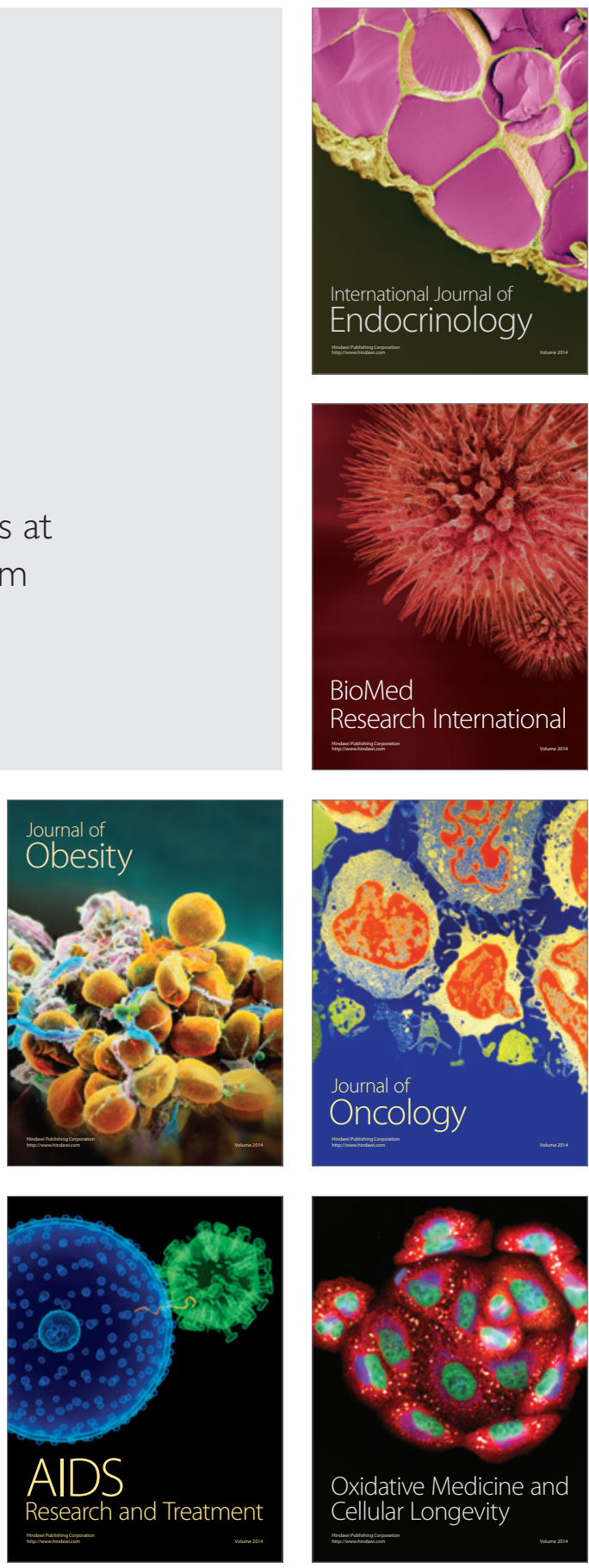